\title{
A Recipe for Success: localism and bounded rationality in lobbying for radiation therapy services in North West Tasmania
}

\author{
S West, E Shannon, E Crisp and T Barnett
}

\begin{abstract}
Objective: Describes where bounded rationality and localism are evident in the debate over the introduction of radiation therapy services in North West Tasmania and how this affected the delivery of the message from each side.
\end{abstract}

Design: Semi-structured interviews with stakeholders and patients/family over an eight month period in 2016 are contrasted with viewpoints identified via document analysis.

Setting: North West Tasmania.

Main Outcome Measures: The mechanisms for policy change and the policy beliefs of each side are examined with the intention of understanding how bounded rationality and a sense of localism can combine to effect policy change.

Results: In the instance of radiation therapy services in North West Tasmania, a policy debate was originally waged between medical professionals and policy makers opposed to a local service on one side and a handful of policy actors advocating for a local service on the other. Those in favour of a local radiation therapy service harnessed a sense of localism to project the perception of widespread community support for the proposal and secured funding commitments during the 2010 Federal Election campaign.

Conclusions: There is evidence of bounded rationality from both the stakeholder and patient groups, as well as a strong sentiment of localism expressed by patients and community advocates. Through understanding this particular case, health service managers can determine how to better time and target messages to the general public and to policy makers during periods of proposed changes to health services.

Key words: radiation therapy services; health service management

\section{Sancia West}

Centre for Rural Health, University of Tasmania,

Launceston, Tasmania, Australia.

Elizabeth Shannon

School of Health Sciences,

University of Tasmania,

Hobart, Tasmania, Australia.

\section{Elaine Crisp}

School of Health Sciences,

University of Tasmania,

Launceston, Tasmania, Australia.

\section{Tony Barnett}

Centre for Rural Health,

University of Tasmania,

Launceston, Tasmania, Australia.

Correspondence:

sancia.west@utas.edu.au

\section{Introduction}

In essence, 'bounded rationality involves the decisionmaker choosing an alternative intended not to maximise his values but to be satisfactory or good enough...(it) enables the administrator faced with a decision to simplify by not examining all possible alternatives'. [1, p.84] The concept of bounded rationality has been used to describe how information is sourced and prioritised in order to allow policy decisions to be made. Individuals are considered to be 'boundedly rational', in that they wish to achieve a particular policy outcome but may be unsure of how to achieve this or how to process all the information relevant to the issue. [2] Originally pioneered by Simon, [3] bounded rationality rests on several principles, which include that people intend to be rational but cognitive and emotional limitations may make them act in non-rational ways, and that limited attention spans can lead people to choose whichever option is 'good 
enough' to meet the minimum aspirational level they have attached to the issue.

The debate over the introduction of radiation therapy services into the North West (NW) Tasmanian region is an example of conflicting priorities: a community desire for more local services versus a stakeholder desire for more centralised services. Prior to 2016 the NW of Tasmania did not have a radiation therapy services and patients from this region were referred to Launceston or Hobart. A mediadriven representation of a community desire to have a regional radiation therapy service began to find traction during the 2000s. It was not until the Federal Election campaign of 2010 that funding was finally committed, in the highly marginal electorate of Braddon, which allowed the service to be built. [4]

The community desire for a local radiation therapy service could be seen as reflecting a deep sense of localism. Localism can result from a sense of shared identity and encourages members of the community to become involved in decisionmaking on issues of local significance. [5] Engagement of the local community in decision-making could achieve, or add to, a balance between government and community needs or expectations.

The community desire for a local service was expressed in several ways, largely via media articles, a petition and a public forum held in 2010. This desire was in contrast to repeated statements by the medical community that a local service was not safe, sustainable or warranted [6-8] and by the State Government that the service needed to be fully funded before it could be considered sustainable. $[9,10]$ It was also in contrast to the perceived need for such a service by the medical community, given the small population size. [6] However, as discussed by Cairney, [11] efforts by any scientific community to challenge a proposed change based on technical or scientific evidence will fail unless two realities are achieved: that policymakers will never think like scientists; and that there is no point in the policy-making process where scientific evidence can be introduced to manifestly impact the result.

Stakeholders, patients and family members were interviewed to determine if examples of bounded rationality and a sense of localism were evident and contrasted these to the viewpoints stated in documents from the period of the policy debate. By aligning major actors with a particular side of the policy debate, this research examined the reasons behind the use of bounded rationality, the interplay between bounded rationality and localism, and how the medical community and State Government might have used an understanding of bounded rationality to better target their message to the general public.

\section{Methods}

To identify and understand instances of bounded rationality and localism, evidence was sourced from both semistructured interviews and document analysis. Documents were sourced from databases, search engines and manual searches and were limited to the year 2000 onwards in order provide a full decade of debate and consistency to develop prior to the funding commitment made in 2010. Documents included journal articles, government and non-government documents, Hansard, media articles, and media releases and statements made by political candidates, representative bodies and other stakeholders.

Interviews were conducted in 2016 with stakeholders, as well as patients and family members from NW Tasmania. A total of 38 participants were interviewed, comprising 15 stakeholders in 14 interviews, with one interview involving an additional last minute participant, and 16 patients and seven family members across 18 interviews, where some spouses were interviewed together and one family member was interviewed without the patient present. Ethics approval was received from the Human Research Ethics Committee (Tasmania).

Stakeholders were initially identified from the document analysis and invited by letter to participate in an interview. Purposive snowball sampling was then used to identify further possible participants. Stakeholders included health bureaucrats, medical professionals, elected representatives, non-government organisation representatives and committee members. Questions related to the identification of actors and policies that impacted on the design and delivery of cancer services.

An opt-in system was used for recruitment of cancer patients and family, with advertising displayed in the local newspapers, health centres and community centres. Interested parties could then contact to express interest in participating. Participants were restricted to those over the age of 18 who were or had been a diagnosed cancer patient or were the direct family member or carer of a patient. Questions asked during interviews related to the accessibility of the system and suggestions for improving accessibility.

Interview transcripts and documents were read and stakeholders were grouped by profession, with patients forming a separate group. These groups were then analysed 
to determine the major beliefs held by each, which were then examined for any perceived instance of boundedly rational behaviour or an expressed sense of localism.

This process involved establishing the scientific evidence presented on the case for radiation therapy services in NW Tasmania and comparing this with the beliefs and actions of policymakers and the local community and the stated rationale for these.

\section{Results}

The document analysis and interviews provide preliminary evidence of one coalition only, constituting state health policy actors - including health bureaucrats or representatives of the State Government - and the health profession. This coalition was bound together by three distinct beliefs:

\section{Safety and Sustainability: patient safety is} compromised if a service cannot be sustained financially or properly resourced.

The cancer instance in Tasmania is increasing because of an ageing population but it hasn't gotten to the level where it would sustain four linear accelerators in the north of the state, it will only sustain just under three. So one of the machines in Launceston will close down and the one in Burnie will open. (Stakeholder 5)

The viability and safety of an isolated single machine radiation oncology unit in the north-west will become a possibility when the critical mass of high specialised staff is achieved at the Launceston General Hospital's Holman Clinic with its third linear accelerator, if cancer rates grow as projected, and if referrals of people with cancer for radiation oncology reach the nationally recommended rate of 52.3 per cent. [12, p.45-46]

2. Recruitment and Retention: recruiting and retaining specialist medical staff is an issue for the NW and would impact sustainability.

It is expected to be more difficult to recruit to the North West Coast and one of the potential risks with a new North West centre is that specialised staff attracted to this area may come from within the existing staff at the LGH. This may produce a situation where both centres are understaffed. [13, p.2]

The major difficulty will be the recruitment and retention of the highly specialised staff necessary to implement and maintain the service. Such a service requires radiation oncologists, specialised nurses, radiation therapists, engineers, medical physicists and other technical staff. All of these personnel are in short supply in Australia. [6]
3. Travel, Transport and Accommodation: providing assistance for patients to travel was a solution to lack of access.

I actually don't think that distance in Tasmania is a critical issue... if people have greater awareness and understanding then the very small distances that we need to travel in Tasmania pale into insignificance. (Stakeholder 3B)

But there are still patients who still need to travel... So if they do have to travel it's about policy decisions making it easier for them to stay overnight and their support person. So it's about equity of access not equality of access. (Stakeholder 6)

These beliefs showed a focus on the machinations of delivering a radiation therapy service and the prioritisation of patient care over geographic accessibility. These beliefs were demonstrated through evidence on the need for a service and the capacity for it to be delivered in terms of human and financial capital, rather than emotive statements.

What the results did not show, however, was any indication of a competing coalition. There were some shared beliefs amongst members of the community around travel being a burden and around the notion of equity. However, there was no group who advocated consistently for a regional service and came together in non-trivial action. There was one person who organised a petition and a forum. There was one journalist who wrote at least 18 articles framing the issue as one of great importance to the NW and involving significant community involvement:

The cancer centre fight is an example of how the politics and lobbyists with vested interests can stack the argument. Politicians did not expect everyone in the region almost to a man, woman and child to back up time and again and refuse to budge from a collective demand to have the cancer centre built in Burnie. [14, p.10]

However, their efforts were made in isolation to each other and with no evidence of community involvement. So how can there be a major change in policy, designed to serve the needs of the community, when no community demand is evident? The results suggest that bounded rationality may have guided policy decision-making in order to facilitate community expectations.

This is highlighted by one member of a non-government organisation involved in cancer services, who stated:

'There have been times when politics have overridden really what is in the best interests of the client... elections have forced particular policies to be enacted.' (Stakeholder 2) 
Another, being a senior specialist, stated:

...money has been inappropriately apportioned to different bits of the state which means that they can't actually provide any proper service anywhere... those sorts of policy decisions are absolutely nonsense.' (Stakeholder 3A)

The results also showed some strong signs of localism amongst the NW community, even if it was not necessarily demonstrated through a formal, active coalition or lobby group.

Stakeholder 1 was heavily involved in lobbying for radiation therapy services and stated that there was a considerable feeling in the NW that they miss out because they don't have a critical mass. The participant stated that forcing NW residents to travel for radiation treatment was unfair and that a local service needed to be built to deliver equity. 'If people needed to come from Melbourne to Burnie for treatment an hour's flight and back is less than having to go through to Launceston or Hobart. So there is a possibility of expanding the clientele.' To summarise, their argument was that people from the NW should not be made to travel to Launceston (being as little as 50 minutes away) but that people from Victoria could travel to NW Tasmania to receive treatment and that this was acceptable. This points to the irrationality and contradictory nature of some beliefs, consistent with the notion of boundedly rational decision-making.

Interestingly, not all the patients interviewed showed a strong sense of localism. Indeed, some were quite vocal in their opposition. One patient stated:

'Regional parochialism has, for want of a better word, buggered the hospital system in Tasmania... They've wasted so much money where they could have a damn good helicopter service.' (Patient 12)

\section{Discussion}

The health and policy coalition could, in terms of bounded rationality, be seen as the 'scientific community' in this particular health sphere. They were the medical professionals and health bureaucrats who understood intimately the service and its complexities. The Tasmania Government (as a state health policy actor) should therefore have been both a coalition member as well as a policy maker, thereby strengthening the link between the 'scientific community' and the decision-making authority. This was true in essence. However the Federal Government's takeover of the issue in the 2010 Federal Election, by committing Federal funding for a state responsibility, changed the dynamics so that the true policymaking power lay with the most hierarchically superior level of government.
The absence of a second coalition to lobby for policy change leads to the question of whether change was agitated for by something or someone other than a consumer coalition. There is a possible role of the media in framing and promoting the issue of radiation therapy services, giving the impression of widespread community support when little more than general community interest existed. Or it could even be that the media, in a demonstration of bounded rationality, stated that there was a community desire for this radiation therapy service. However, in reality there is little evidence of having been a 'community desire' at all when it came to this issue.

In terms of understanding the actions of policymakers, bounded rationality can be seen. Acting on the desire to be elected or re-elected, the political parties vying for power in the 2010 Federal Election gathered enough information to form the basis of a decision, one that could win public support. This decision was that the community desired a radiation therapy service in the NW and that building a service in that region was the pre-packaged solution. Other alternatives, regardless of how clearly they were articulated or how strongly these were promoted by the 'experts' in the field, could not find traction in the midst of this boundedly rational decision-making.

But would this change have occurred without the intervention of the Federal Government? The evidence here is mixed. On one hand, Braddon was a marginal seat in what was going to be a close election. On the other hand, funding had previously been concentrated on the Launceston service, including a 2007 commitment that led to a third linear accelerator there. Significantly, discussion over the possible funding of radiation therapy services only became noticeable after a petition was presented to State Parliament in 2010 on the eve of a public forum in the lead up to the election. This indicates that the move from no radiation therapy to a radiation therapy service reached a marked increase in momentum during the Federal election campaign of 2010, after no clear timeline from the State Government for achieving this change. Indeed, part of the decision to place a third linear accelerator in Launceston, rather than establishing a service in the NW, had come down to issues of sustainability and recruitment, indicating the State Government concurred with the views of the health community. [13] Therefore, change was clearly instigated at a Federal level.

Understanding the reality of bounded rationality in policymaking allows health professionals and those involved in health policy to be more strategic in what they say and 
when they say it. As Cairney [11] states, there is no one point in the policy process at which scientists or experts can step in and have a significant effect on the outcome. The process is more chaotic, more emotive and less logical than that. By understanding the limitations to a policymaker's receptiveness to new information, even in the face of credible new information, health experts can target messages more effectively.

Skinner [15] discusses the idea of being more strategic using the concept of 'defensive localism' to discuss proposed changes to local health networks in Canada. Some of the networks affected, rather than fighting the changes, used the opportunity to secure additional funding in return for their acquiescence. Therefore, if health professionals or managers could frame the issue in terms of what the affected groups might be able to secure or gain if they supported evidence-based changes then these groups might take that opportunity. Likewise, health professionals and management might realise that their organisations are the ones needing to acquiesce and could use this understanding to bargain for a better outcome. The consequence of using this understanding and being more strategic with policy actions may well mean a more safe and sustainable service for patients, even if that patient group is seemingly lobbying for a different outcome.

\section{Conclusion}

This paper has examined how political strategy used to win support in a marginal seat during a marginal election reveals the use of boundedly rational decision-making in the establishment of radiation therapy services. The efforts of the scientific community, namely health bureaucrats and health professionals, were to highlight the lack of sustainability and safety in such a service and the ongoing issues of recruiting and retaining specialist oncology and radiation therapy staff. The Tasmanian Government had also refrained from moving forward on establishing a radiation therapy service in the NW for the same reasons. It was not until the commitments made by the Federal Government in 2010 that the Tasmanian Government was left with no choice but to proceed.

Yet, the decision to commit funding does not appear to be based on any evidence presented that there was a need for this service in the NW region. The evidence, indeed, supported the contrary. What was evident was a sense of localism in the region that made the establishment of radiation therapy services a pre-packaged solution aimed at meeting the aspirational objectives of the Federal
Government to be re-elected in 2010. This article provides health service professionals and managers with an opportunity to understand the political, boundedly rational motivations that underpin policy change and the incorporate this understanding into their own policy objectives.

\section{Competing Interests}

The authors declare that they have no competing interests.

\section{References}

1. Ham C, Hill M. The Policy Process in the Modern Capitalist State. 2nd ed. California: Harvester Wheatsheaf; 1993.

2. Jenkins-Smith H, Nohrstedt D, Weible C, Sabatier P. The Advocacy Coalition Framework: foundations, evolution, and ongoing research. In: Sabatier P, Weible C, editors. Theories of the Policy Process. 3rd ed. Boulder, Colorado: Westview; 2014.

3. Simon H. Administrative behaviour: A study of decision-making processes in administrative organizations. New York: Macmillan 1947.

4. Australia, Senate Community Affairs Committee. Answers to Estimates Questions on Notice - Health and Ageing Portfolio. Australian Government; 2011.

5. Dare M. Localism in practice: insights from two Tasmanian case studies. Policy Studies. 2013;34(1):592-611.

6. Radiotherapy machine not feasible at NWRH [press release]. AMA Tasmania, 14 January 2010.

7. Linear Accelerator North West Regional Hospital [press release]. AMA Tasmania, 7 August 2010.

8. Clinical Oncological Society of Australia. Mapping Rural and Regional Oncology Services in Australia. Clinical Oncological Society of Australia; 2006.

9. The Advocate. They'd riot for cancer services in Hobart. The Advocate. 201014 July.

10. The Advocate. Labor questions Libs promise of cancer funding. The Advocate. 20106 August.

11. Cairney P. The politics of evidence-based policymaking. The Guardian. 201610 March.

12. Tasmania, House of Representatives. Debates. Hobart: Tasmanian Government; 2010. p. 29-93.

13. Contract Review Committee. Additional Radiation Oncology Treatment Unit for Northern Tasmania. Hobart: Tasmanian Government; n.d.

14. Bingham L. Recruitment drive for centre. The Advocate. 2014 28 March.

15. Skinner M, Jospeh A, Herron R. Voluntarism, defensive localism and spaces ofresistance to health care restructuring. Geoforum. 2016;72(1):67-75. 